\title{
Parental depression, maternal antidepressant use during pregnancy, and risk of autism spectrum disorders: population based case-control study
}

\author{
(c) $(1)$ (9)
}

\author{
Dheeraj Rai clinical lecturer ${ }^{123}$, Brian K Lee assistant professor ${ }^{4}$, Christina Dalman associate \\ professor $^{2}$, Jean Golding professor emeritus ${ }^{5}$, Glyn Lewis professor ${ }^{1}$, Cecilia Magnusson professor ${ }^{2}$
}

${ }^{1}$ Centre for Mental Health, Addiction and Suicide Research, School of Social and Community Medicine, University of Bristol, Bristol BS8 2BN, UK; ${ }^{2}$ Division of Public Health Epidemiology, Department of Public Health Sciences, Karolinska Institutet, Stockholm, Sweden; ${ }^{3}$ Avon and Wiltshire Partnership Mental Health NHS Trust, Bristol, UK; ${ }^{4}$ Department of Epidemiology and Biostatistics, Drexel University School of Public Health, Philadelphia, PA, USA; ${ }^{5}$ Centre for Child and Adolescent Health, School of Social and Community Medicine, University of Bristol, UK

\begin{abstract}
Objective To study the association between parental depression and maternal antidepressant use during pregnancy with autism spectrum disorders in offspring.

Design Population based nested case-control study.

Setting Stockholm County, Sweden, 2001-07.

Participants 4429 cases of autism spectrum disorder (1828 with and 2601 without intellectual disability) and 43277 age and sex matched controls in the full sample (1679 cases of autism spectrum disorder and 16845 controls with data on maternal antidepressant use nested within a cohort $(n=589114)$ of young people aged $0-17$ years.

Main outcome measure $A$ diagnosis of autism spectrum disorder, with or without intellectual disability.

Exposures Parental depression and other characteristics prospectively recorded in administrative registers before the birth of the child. Maternal antidepressant use, recorded at the first antenatal interview, was available for children born from 1995 onwards.

Results A history of maternal (adjusted odds ratio 1.49, 95\% confidence interval 1.08 to 2.08 ) but not paternal depression was associated with an increased risk of autism spectrum disorders in offspring. In the subsample with available data on drugs, this association was confined to women reporting antidepressant use during pregnancy $(3.34,1.50$ to $7.47, \mathrm{P}=0.003$ ), irrespective of whether selective serotonin reuptake inhibitors (SSRIs) or non-selective monoamine reuptake inhibitors were reported. All associations were higher in cases of autism without intellectual disability, there being no evidence of an increased risk of autism with intellectual disability. Assuming an unconfounded, causal association, antidepressant use during pregnancy explained $0.6 \%$ of the cases of autism spectrum disorder.
\end{abstract}

Conclusions In utero exposure to both SSRIs and non-selective monoamine reuptake inhibitors (tricyclic antidepressants) was associated with an increased risk of autism spectrum disorders, particularly without intellectual disability. Whether this association is causal or reflects the risk of autism with severe depression during pregnancy requires further research. However, assuming causality, antidepressant use during pregnancy is unlikely to have contributed significantly towards the dramatic increase in observed prevalence of autism spectrum disorders as it explained less than $1 \%$ of cases.

\section{Introduction}

The estimated prevalence of autism spectrum disorders in the United States has dramatically increased from fewer than 5 in 10000 children in the 1980 s to 1 in 88 in $2008 .^{1}$ Similar increases have been reported in much of the Western world. ${ }^{2}$ Better recognition and more inclusive diagnostic criteria for autism spectrum disorders may explain this rising prevalence, but a real increase in incidence has not been ruled out. ${ }^{1}$

Relatively little is known about the causes of autism spectrum disorders and both genetic and environmental factors are implicated. ${ }^{3}$ The identification of modifiable environmental risk factors may aid in the primary prevention of some cases.

A recently reported association between use of selective serotonin reuptake inhibitor (SSRI) antidepressants during pregnancy and autism spectrum disorders in offspring has raised the possibility of discovering one such modifiable causal factor. ${ }^{4}$ There is increasing interest in the role of the serotonergic system in the pathophysiology of autism, and prenatal exposure to serotonergic agents is a biologically plausible pathway. ${ }^{5}$ SSRIs have increasingly been used in the treatment of depression 
during pregnancy since the 1990 s, mirroring the secular rise in the observed prevalence of autism spectrum disorders. ${ }^{4}$

However, an association between SSRI use during pregnancy and autism may not imply a causal relation. An alternative explanation is confounding by indication-the possibility that maternal depression is responsible for the associations observed between SSRIs and autism spectrum disorders in offspring. ${ }^{45}$ Although the relation between parental depression and risk of autism spectrum disorders is often assumed to be well established and has a genetic origin, ${ }^{46}$ the supporting evidence is relatively weak. Two recent meta-analyses were inconclusive and reported a lack of studies with psychiatric diagnosis of parents before the birth of the child. ${ }^{7}$

In a large population based study in Sweden, we investigated whether maternal or paternal depression identified before the birth of the child is associated with autism spectrum disorders in offspring; whether maternal antidepressant use during pregnancy is associated with autism spectrum disorder in offspring, and, if so, whether this explains any associations between maternal depression and autism; whether any associations between antidepressants and autism are unique to SSRIs or also evident for other antidepressants; and whether all the above associations are similar in offspring with autism with and without comorbid intellectual disability.

\section{Methods}

We conducted a case-control study nested within the Stockholm youth cohort, which comprises all young people aged 0 to 17 years, residing in Stockholm County between 2001 and 2007 $(\mathrm{n}=589114){ }^{2}$ The cohort contains prospectively recorded data on the probands and their first degree relatives collected by record linkage with national and regional healthcare, social, and administrative registries using unique national identity numbers assigned to all Swedish residents. ${ }^{2}{ }^{9} 10$

Sweden has a well developed system of publicly funded screening, diagnostic, and follow-up services relevant to autism spectrum disorders, with national and regional registers recording information about diagnosis and other details. ${ }^{2}$ Assessments for autism spectrum disorder are typically carried out by child neuropaediatric or mental health services, and, as per local guidelines, include diagnostic evaluations covering the child's social, medical, and developmental history after interviews with the parents, observation of the child, and a structured neuropsychiatric assessment including cognitive testing. ${ }^{211} \mathrm{We}$ identified children with autism spectrum disorders in the Stockholm youth cohort using a multisource case ascertainment method, with registers covering all pathways of autism diagnosis and care within Stockholm County. ${ }^{2}$ Diagnoses recorded in these registers (codes from the international classification of diseases, ninth and 10th revisions, ICD-9 (299) and ICD-10 (F84), respectively, or Diagnostic and Statistical Manual of Mental Disorders, fourth edition, (299)) were supplemented by a record of care in specialist centres for autism with and without intellectual disability, where an autism diagnosis and cognitive testing is a prerequisite. We also identified comorbid intellectual disability status using ICD-9 (317-319), ICD-10 (F70-79), and DSM-IV (317-319) in the child or adult mental health registers or the national patient register. ${ }^{2}$ As of 31 December 2007, over 5000 cases of autism spectrum disorder have been identified in the Stockholm youth cohort, almost $43 \%$ of whom have a comorbid intellectual disability. ${ }^{2}$ Two validation procedures - a case note validation study by a consultant child psychiatrist and a neuropaediatrician and a cross validation study with a national twin study — both found a high validity of the diagnoses for autism spectrum disorder recorded in the registers used for case ascertainment. ${ }^{2}$

Figure $1 \Downarrow$ shows the derivation of the sample for the present analyses. To ensure completeness of diagnostic data for parent and children in the registers we excluded from the study sample those with missing maternal identification numbers, adopted children, those living in Stockholm County for less than four years (thus also excluding all children aged 0-3 years who would be too young to have a reliable diagnosis). In the remaining population of the Stockholm youth cohort, we matched each case of autism spectrum disorder to 10 living controls without autism by date (month and year) of birth and sex (fig 1).

\section{Parental history of depression}

We identified the psychiatric history of parents using two sources: the Stockholm County adult psychiatric outpatient register, which records the dates and diagnoses for any contact with specialist outpatient psychiatric services in Stockholm County since $1997,{ }^{12}$ and the Swedish national patient register, which contains the dates and discharge diagnoses of all inpatients (since 1973) and specialist outpatients (since 2001, although with incomplete psychiatric outpatient data) in Sweden. ${ }^{13}$ Using these sources, we identified mothers and fathers with depression if they had a registered diagnosis of a depressive episode, recurrent depressive disorder, persistent mood disorder, and other or unspecified mood disorder (see supplementary table S1 for ICD codes). To avoid the possibility of reverse causality we considered only diagnoses recorded before the birth of the child participating in the study.

We used two approaches to handle the presence of more than one recorded diagnosis for a parent. In our primary strategy, we used a hierarchy based on ICD-10, ${ }^{14}$ adapted for a greater relevance to autism and our research question. This (from higher to lower priority) included schizophrenia or non-affective psychoses or bipolar disorder; neurodevelopmental disorders or personality disorders; alcohol and drug disorders; and depression, anxiety, and somatoform or other disorders (see supplementary table S1 for ICD codes). Depression was therefore coded conservatively, only higher than anxiety or somatoform disorders in case of multiple diagnoses. We grouped other diagnoses into anxiety disorders, psychotic disorders (including schizophrenia and bipolar disorder), and other non-psychotic disorders for use as potential confounders in analysis. In an alternative strategy we allowed participants to be included in the different diagnostic groups if more than one diagnosis had been recorded (and adjusted for these in our regression models).

\section{Maternal antidepressant use during pregnancy}

Since 1995 the Swedish medical birth register ${ }^{15}$ contains data on current drug use reported by mothers at their first antenatal interview (median 10 weeks' gestation), ${ }^{16}$ coded using the World Health Organization's ATC codes (www.whocc.no/atc_ddd_ index/). Thus for mothers of children born from 1995 onwards we retrieved data on any antidepressant use (ATC code N06A), further divided into the two most commonly used antidepressant classes-SSRIs (ATC code N06AB) and non-selective monoamine reuptake inhibitors (ATC code N06AA), which comprises tricyclic antidepressants (see supplementary table S2 for individual drugs in each group). We could not study other antidepressant categories since their use in pregnancy was rare. For the same reason we did not study individual drugs within any class. The medical birth register has been shown to identify 
$78 \%$ of all antidepressants prescribed during the first trimester, ${ }^{17}$ and the drug name registered in prescription records and that recorded in the register has been reported to show high concordance $(97 \%){ }^{16}{ }^{17}$

\section{Other characteristics}

We used prospectively collected data on several parental characteristics as potential confounders: maternal age $(<20$, $20-24,25-29,30-34,35-39,>40$ years $)$ and paternal age $(<25$, $25-29,30-34,35-39,40-49,>50$ years) at birth of child, fifths of family income adjusted for year of ascertainment and family size, highest education of either parent $(\leq 9,10-12, \geq 13$ years), highest occupational class of either parent (higher professionals, intermediate non-manual employees, lower non-manual employees, skilled manual workers, unskilled manual workers, self employed, or unclassified), maternal region of birth (Sweden, Europe, Americas, Africa, Asia, or Oceania), parity $(0,1,2, \geq 3$ previous births). These characteristics were chosen because of their association with autism in the literature. ${ }^{791018}$

We also considered variables with relatively less empirical evidence linking them to autism but which nevertheless may be confounders on theoretical grounds, including maternal smoking reported at the first antenatal interview (non-smoker, 1-9 or $\geq 10$ cigarettes per day), and a diagnosis of maternal diabetes (yes or no) or hypertension (yes or no). We considered these in additional analyses since they had a greater proportion of missing data (18\% for maternal smoking and 9\% for diabetes and hypertension). We also considered birth weight for gestational age (normal for gestational age, small for gestational age, large for gestational age $),{ }^{19}$ gestational age at birth $(\leq 32$, $33-36,37-42, \geq 43$ weeks), ${ }^{19}$ and Apgar score at five minutes $(<7 \text { or } \geq 7)^{72021}$ in separate analyses as these are potential mediators (for example, fetal growth) $)^{22}$ but adjusting for them could result in biased estimates. ${ }^{23}$

\section{Statistical analysis}

All analyses were conducted using Stata 10.1 for Windows. In descriptive analysis we calculated proportions of individuals with autism spectrum disorder (and autism with and without intellectual disability) with the exposure variables and other covariates. Using conditional logistic regression models, we derived odds ratios and their $95 \%$ confidence intervals as estimates of relative risks for the relation between a history of depression in each parent and autism spectrum disorder in offspring as a group, and dichotomised into autism with or without intellectual disability. After estimating crude associations, we adjusted for parental ages, parental income, education, occupation, region of birth, and parity (model 1). In model 2, we further adjusted model 1 for other psychiatric disorders in the parent, and in model 3 we adjusted model 2 for the presence of psychiatric disorders in the other parent. We conducted these analyses in a sample with all available data and those with complete data on all covariates (here we report the latter analysis to ensure consistent numbers across all the models; in the supplementary tables we present analyses using all available data). We used the $\chi^{2}$ test of heterogeneity to calculate $\mathrm{P}$ for heterogeneity values to assess the statistical significance of any differences between estimates for paternal and maternal depression and for autism with and without intellectual disability.

We conducted several secondary analyses for a better understanding of the implications and robustness of these findings. Since we did not have data on antidepressants for the full cohort, to assess whether any observed relations existed before the majority of SSRIs were licensed in Sweden and came into use during pregnancy, we restricted the sample to births before 1990 (children born between 1984 and 1989). We also repeated the analysis on children of primiparous women only, to avoid the possibility of observations being due to depression in mothers related to an older sibling with autism or other developmental concerns. Thirdly, we restricted the analysis to parents who were born in Sweden since we have previously observed noticeably different associations of autism with and without intellectual disability in relation to parental immigration to Sweden, ${ }^{9}$ and a low take-up of psychiatric services in migrant adults has been anecdotally reported. Fourthly, we repeated the main analyses using the alternative coding of psychiatric disorders, allowing for multiple psychiatric diagnoses in the parents. Finally, we repeated the analyses in a sample of children at least 8 years old (born between 1984 and 1999) since the diagnosis of autism spectrum disorder may be most reliable in older children.

To include the antidepressant data, we restricted the sample to births from 1995 onwards and repeated the analysis for maternal depression, adjusting for antidepressant use during pregnancy. We then estimated the associations using a categorical variable to denote mothers with no history of depression and no antidepressant use during pregnancy, a history of depression but no antidepressant use during pregnancy, a history of depression and antidepressant use during pregnancy, and antidepressant use reported during pregnancy but no recorded history of depression. Finally, we estimated the risk of autism spectrum disorder with antidepressant use during pregnancy, irrespective of indication, and repeated these analyses after classifying antidepressants into SSRIs and non-selective monoamine reuptake inhibitors. For these analyses we excluded a small number of mothers reporting multiple antidepressant use. We adjusted these analyses for parental ages, income, education, occupation, migration status, parity, and a variable depicting any psychiatric disorder in the mother. In a separate analysis we further adjusted for any other psychotropic drug use except antidepressants. We used the resulting adjusted odds ratios (OR) and prevalence of exposure to antidepressants in cases $(\mathrm{PE})$ to estimate population attributable fractions (PAF) using the formula: $[\mathrm{PAF}=\mathrm{PE}(\mathrm{OR}-1) / \mathrm{OR}]$. The population attributable fractions denote the proportion of cases with autism that could be prevented if antidepressant use was completely eliminated from the population, assuming the association was causal and all confounders had been accounted for.

\section{Results}

\section{Parental depression and autism spectrum disorder}

The characteristics of cases and controls with all available data were similar to the 4429 cases ( 1828 with a recorded intellectual disability and 2601 without) and 43277 controls with complete data that we used in our main analysis (table $1 \Downarrow$ ). Approximately $1 \%(n=44)$ of mothers of the 4429 case children with autism spectrum disorder had depression as defined by our hierarchical classification, recorded before the birth of the index child, compared with $0.6 \%(n=272)$ of 43277 control mothers (table 1). A paternal history of depression was found in approximately $0.4 \%$ of cases $(n=19)$ as well as in controls $(n=155)$.

Table $2 \Downarrow$ shows the associations between maternal and paternal history of depression and the risk of autism spectrum disorder and autism with and without intellectual disability. Maternal depression was associated with an approximately $60 \%$ increase in risk of autism spectrum disorder (crude odds ratio 1.61, 95\% 
confidence interval 1.17 to $2.23, \mathrm{P}=0.004$ ), which was not substantially attenuated after adjustment for all potential confounders. When autism spectrum disorders were dichotomised between those with and those without intellectual disability, it was apparent that the increased risk of autism with maternal depression largely resulted from an almost twofold odds of autism without intellectual disability (adjusted odds ratio $1.86,95 \%$ confidence interval, 1.25 to $2.77, \mathrm{P}=0.002$ ), there being no evidence for an increased odds of autism with intellectual disability. The odds ratio for autism spectrum disorder with and without intellectual disability were statistically different $(\mathrm{P}$ for heterogeneity=0.04). There was no evidence for an association between depression in fathers and autism spectrum disorder in offspring, irrespective of intellectual disability (table 2), but there was no statistical evidence for a difference between the results for maternal and paternal depression ( $\mathrm{P}$ for heterogeneity=0.71).

A similar pattern of associations was observed in the analysis repeated on a sample restricted to offspring born before 1990, children of primiparous women, and children of parents who were born in Sweden, in the analysis using a non-hierarchical coding of psychiatric disorders and in the analysis restricted to children at least 8 years old (fig $2 \Downarrow$, see supplementary tables S3 to S7). In all these analyses, an increased risk of autism spectrum disorder largely without intellectual disability (with no increased risk with intellectual disability) was observed with a maternal history of depression. The associations remained robust when in a smaller sample the regression models were further adjusted for birth weight for gestational age, gestational age at birth, Apgar score at five minutes, maternal smoking, and recorded maternal diabetes or hypertension (see supplementary table S8).

\section{Maternal depression, antidepressant use during pregnancy, and autism spectrum disorder}

We had information about antidepressant use during pregnancy for 1679 cases of autism spectrum disorder (743 with intellectual disability and 936 without) and 16845 control children who were born from 1995 onwards. The associations of maternal depression and autism spectrum disorder in this sample followed a similar trend, albeit with wide confidence intervals (adjusted odds ratio $1.40,95 \%$ confidence interval 0.91 to 2.17 ), largely resulting from associations for autism without intellectual disability $(1.69,0.97$ to 2.97 , table $3 \Downarrow)$. These estimates attenuated on adjustment for maternal antidepressant use during pregnancy (models 1 and 3, table 3).

Table $4 \Downarrow$ shows the results of analysis using the variable combining a maternal history of depression and antidepressant use during pregnancy. Offspring of mothers with a history of depression who reported antidepressant use during pregnancy seemed to have strong associations with autism spectrum disorder, which were also confined to autism without intellectual disability and remained robust in adjusted models. A history of depression without antidepressant use during pregnancy was not associated with a heightened risk of autism spectrum disorder (table 4).

Table $5 \Downarrow$ shows the associations between antidepressant use and autism spectrum disorder. Any antidepressant use during pregnancy in mothers of cases was $1.3 \%$ compared with $0.6 \%$ of controls equating to an almost twofold increase in risk of autism spectrum disorder (1.90, 1.15 to 3.14$)$. These associations too were largely observed due to associations with autism without intellectual disability $(2.54,1.37$ to 4.68$)$ with no increased odds for autism with intellectual disability. In an additional analysis we also explored the potential confounding effect of any other psychiatric drugs by adjusting for this in the adjusted model in table 5; these did not result in any noticeable change to the results: fully adjusted odds ratio for any antidepressant use during pregnancy 1.83 (1.10 to3.04), autism with intellectual disability 1.09 (0.41 to 2.91$)$, and autism without intellectual disability 2.37 (1.27 to 4.44). Similar results were evident for maternal use of both SSRIs and non-selective monoamine reuptake inhibitor antidepressants, although numbers were small and confidence intervals relatively wide (table 5). The population attributable fraction estimate suggested that, assuming an unconfounded causal association, $0.6 \%$ of cases of autism spectrum disorder could be prevented if antidepressant use during pregnancy was completely eliminated.

Finally, the results of analyses using all available data instead of a complete case sample (see supplementary tables S9-S12) were similar to those presented in tables 2 to 5 .

\section{Discussion}

A maternal history of depression was associated with a higher risk of autism in offspring, but there was no evidence of a relation with paternal depression. These associations were largely limited to children of mothers who reported using antidepressants at the first antenatal interview. The increased risk was observed with SSRIs as well as with other monoamine reuptake inhibitor antidepressants. All these increased risks seemed to be confined to autism spectrum disorders without intellectual disability and persisted after adjustment for several confounding factors.

\section{Comparison with previous studies}

To our knowledge, only one previous study, using data on 298 cases of autism spectrum disorders and 1507 control children in northern California, simultaneously studied maternal depression as well as antidepressant use during pregnancy and risk of autism. ${ }^{4}$ This study reported a twofold increase in risk of autism spectrum disorder with a prescription for an SSRI during the year before pregnancy but no increase with maternal depression in the absence of antidepressant prescription. ${ }^{4}$ However, no association between antidepressants other than SSRIs and autism was found, but the numbers were small and the authors highlighted the need for further work.

Our findings of an association between antidepressant use during pregnancy and autism spectrum disorders based on a much larger sample is consistent with the above findings despite a different socioeconomic patterning of autism spectrum disorders in Sweden ${ }^{10}$ and relatively conservative prescribing during pregnancy compared with the United States. ${ }^{4} \mathrm{We}$ additionally highlight the specificity of these findings to children with autism without intellectual disability, which include those termed as having "high functioning autism" and Asperger syndrome. Furthermore, we found that non-SSRI antidepressants may also be associated with a heightened risk of autism, an association that was not observed by in the US study, ${ }^{4}$ possibly because of low numbers.

Several previous studies have attempted to characterise the association between parental depression and autism spectrum disorders, although they had no data on drugs. However, limitations such as small samples, lack of prospective data, long periods of recall, and the inability to study depression separately from other psychiatric (particularly affective and non affective psychotic) disorders, made causal inferences difficult and led to inconclusive meta-analyses. ${ }^{78}$ More recent population based 
studies have also not been able to rule out reverse causality, ${ }^{6}$ study the specific associations between depression and autism spectrum disorders, ${ }^{24}$ or differentiate between maternal and paternal depression. ${ }^{25}{ }^{26} \mathrm{It}$ is notable that despite the uncertainty in the literature, it is commonly assumed that a causal association with parental depression exists and that it occurs through a genetic pathway. ${ }^{46}$

\section{Potential mechanisms}

Our finding that maternal but not paternal depression was associated with autism spectrum disorders is noticeable in some previous studies ${ }^{65}$ but has escaped attention. An association with depression in fathers cannot, however, be ruled out, since the numbers were few and confidence intervals relatively wide. However, our findings suggest that caution is warranted before concluding that an association between parental depression and autism in offspring reflects common genetic pathways ${ }^{4}$; any such pathways would have to explain the seemingly discrepant risks between maternal compared with paternal depression and autism spectrum disorders.

An alternative explanation is that the heightened risk for maternal depression and autism is conferred through an environmental pathway such as in utero exposure to serotonergic agents. It has been estimated that over $20 \%$ of children with autism spectrum disorder have hyperserotonaemia. ${ }^{5}$ Serotonin can be detected in the fetal brain by the fifth week of gestation and is involved in critical neurodevelopmental processes including neurogenesis or neuronal removal, or both; neuronal differentiation; and synaptogenesis. ${ }^{27}$ Antidepressants cross the placental barrier, and intrauterine exposure to serotonergic agents has been shown to promote persistent changes in brain circuitry, decreased serotonergic reactivity, and behavioural features analogous to autism in animal models. ${ }^{28-31}$

Although SSRIs selectively act on the serotonergic system, almost all other antidepressants also have serotonergic activity. ${ }^{32}$ Therefore if in utero exposure to serotonin was a possible causal mechanism, an association with non-selective monoamine reuptake inhibitors would be expected. The increased risks of autism spectrum disorders observed with maternal depression in children born before SSRIs started being used in Sweden further highlight the argument that SSRIs are unlikely to be the sole explanatory mechanism in these observations.

Other potential environmental pathways may also explain the observed associations. For instance, antidepressant use may be a marker of the severest forms of depression during pregnancy. It should be noted that while the antidepressant data were contemporaneous, the depression diagnosis in the US study ${ }^{4}$ and our study was not restricted to pregnancy. It was therefore impossible to ascertain whether the antidepressant use was a marker for active depression during pregnancy, which has been hypothesised to affect "fetal programming" of the hypothalamic-pituitary-adrenal axis as a result of chronically raised levels of glucocorticoids. ${ }^{33}$ However, although this environmental "stress" hypothesis of autism has some empirical support, mainly in animal models, the literature in humans is limited and inconsistent. ${ }^{33}$ Yet another hypothesis which has support in animal models, but with insufficient evidence in humans, is the association between immune activation and infections related to depression and autism in offspring. ${ }^{35} 36$ Other explanations such as alcohol or drug use during pregnancy not severe enough to require health services are plausible.

It is important to note that all the associations were consistently observed for autism spectrum disorders without intellectual disability; and this reinforces the possibility that autism with and without intellectual disability may have partly different causes, and efforts should be made to study them separately. ${ }^{9}$ The idea of a differential association between parental depression and autism based on intellectual disability has been highlighted previously, ${ }^{37}$ but the mechanisms behind these findings are unclear and require further work.

\section{Limitations of the study}

Several limitations of this study need to be acknowledged. Firstly, depression was identified using specialist psychiatric care records and therefore was certainly under-ascertained, since most people with depressive disorders do not seek help or are managed in primary care. It was also not possible to assess either the severity or the course of depressive symptoms in relation to the pregnancy. This is common to all previous population based studies on this topic, ${ }^{64-26}$ and would have led to an underestimation of the odds ratios between depression and autism spectrum disorder if non-differential in relation to autism. ${ }^{38}$ However, a bias in either direction is also theoretically possible, since depression is a debilitating disorder characterised by lack of energy and motivation, possibly leading to depressed women not seeking help for developmental problems in their children; or conversely, services more promptly assessing and recognising autism in children of women already known to psychiatric services (Berksonian bias).

Although autism spectrum disorders were also ascertained through service use, our multisource case ascertainment approach is likely to have minimised outcome misclassification, compared with studies ascertaining autism spectrum disorders solely from inpatient records. The antidepressant data were abstracted from the first antenatal interview (median approximately 10 weeks' gestation) and were only available for cohorts born from 1995 onwards, limiting our statistical power and warranting caution when comparing with results of the larger study. Although the possibility of some reporting bias in these data cannot be excluded, the contemporaneously recorded report of the drugs the mother was taking at the antenatal interview are more likely to reflect actual use than studies utilising prescription data (for which use and compliance is often impossible to ascertain).

Importantly, it is not possible to conclude whether the association between antidepressant use and autism spectrum disorder reflects severe depression during pregnancy or is a direct effect of the drug. There was insufficient power to investigate a record of depression during the immediate prenatal period, which would have allowed further scrutiny of this possibility. The under-ascertainment of depression may have led to partial control for confounding in the relation between antidepressant use and autism spectrum disorder in offspring. Assuming a non-differential misclassification of depression and no qualitative interactions between depression and antidepressant use in relation to autism, the true odds ratio for the relation between antidepressant use and autism spectrum disorder can be estimated to lie between the crude and the adjusted estimates presented. ${ }^{39}$ However, residual confounding due to other unmeasured characteristics cannot be ruled out.

\section{Implications and future directions}

Caution is required before making causal assumptions or clinical decisions based on observational studies. However, it is unlikely that conclusive randomised trial evidence on this issue will ever be available since pregnant women are routinely excluded from drug trials, and even if ethically permissible, such a study would require a very large sample and a relatively long period of 
follow-up. It is therefore likely that a consensus on the potential risk of antidepressant use during pregnancy in relation to autism in offspring will be developed, as further observational data either supporting or refuting these findings are published.

Until that happens, the results of the present study as well as the US study ${ }^{4}$ present a major dilemma in relation to clinical advice to pregnant women with depression. If antidepressants increase the risk of autism spectrum disorder, it would be reasonable to warn women about this possibility. However, if the association actually reflects the risk of autism spectrum disorder related to the non-genetic effects of severe depression during pregnancy, treatment may reduce the risk. Informed decisions would also need to consider weighing the wider risks of untreated depression ${ }^{40}{ }^{41}$ with the other adverse outcomes related to antidepressant use. ${ }^{40-46} \mathrm{With}$ the current evidence, if the potential risk of autism were a consideration in the decision making process, it may be reasonable to think about, wherever appropriate, non-drug approaches such as psychological treatments. However, their timely availability to pregnant women will need to be enhanced. From a public health perspective, if antidepressant use had a causal relation with autism spectrum disorders, it would explain less than $1 \%$ of cases, and therefore would be unlikely to explain the dramatic increase in the observed prevalence of these disorders. Future, larger studies, with access to both diagnostic and treatment data at multiple stages of pregnancy may help disentangle the role of maternal depression and the individual drugs used to treat it in the risk of autism spectrum disorder.

We thank Henrik Dal and Michael Lundberg, statisticians at the Department of Public Health Sciences, Karolinska Institutet for their contributions to data management and the coding of key variables used in this paper.

Contributors: DR, CM, and BKL had the research idea, and CD, JG, and GL helped with its development. DR conducted the analysis and wrote the first and subsequent drafts of the paper with important intellectual input from all coauthors. All authors had full access to the data, specifically, the statistical reports and tables arising from the data, and take responsibility of the integrity of the data and accuracy of the data analysis. All authors have approved the final version of the manuscript submitted for publication. DR and CM act as guarantors.

Funding: This study was funded by the Swedish Research Council (grant No 2012-3017). The data linkages and staff costs have also been supported by grants from the Stockholm County Council (2007008), Swedish Council for Working Life and Social Research (2007-2064), Swedish Research Council (523-2010-1052), and Swedish Regional agreement on medical training and clinical research (ALF). No funder had any role in the study design; data collection, analysis, or interpretation; in the writing of the report; or in the decision to submit the article for publication. The views expressed are those of the authors and not necessarily those of any of the funders or organisations they represent.

Competing interests: All authors have completed the ICMJE uniform disclosure form at www.icmje.org/coi_disclosure.pdf (available on request from the corresponding author) and declare: no support from any organisation for the submitted work; no financial relationships with any organisations that might have an interest in the submitted work in the previous three years; no other relationships or activities that could appear to have influenced the submitted work.

Ethical approval: This study was approved by the research ethics committee at Karolinska Institutet, Stockholm (DNR 2007/545-31 for main Stockholm youth cohort record linkages, and DNR 2011/1393-32 for additional linkage of maternal antidepressant use data).

Data sharing: No additional data available.
Prevalence of autism spectrum disorders-Autism and Developmental Disabilities Monitoring Network, 14 sites, United States, 2008. MMWR Surveill Summ 2012;61:1-19. Idring S, Rai D, Dal H, Dalman C, Sturm H, Zander E et al. Autism spectrum disorders in the Stockholm Youth Cohort: design, prevalence and validity. PloS one 2012;7:e41280. 3 Hallmayer J, Cleveland S, Torres A, Phillips J, Cohen B, Torigoe T, et al. Genetic heritability and shared environmental factors among twin pairs with autism. Arch Gen Psychiatry 2011;68:1095-102.

4 Croen LA, Grether JK, Yoshida CK, Odouli R, Hendrick V. Antidepressant use during pregnancy and childhood autism spectrum disorders. Arch Gen Psychiatry 2011;68:1104-12.

5 Levitt P. Serotonin and the autisms: a red flag or a red herring? Arch Gen Psychiatry 2011;68:1093-4.

6 Daniels JL, Forssen U, Hultman CM, Cnattingius S, Savitz DA, Feychting M, et al. Parental psychiatric disorders associated with autism spectrum disorders in the offspring. Pediatrics 2008;121:e1357-62.

7 Gardener H, Spiegelman D, Buka SL. Prenatal risk factors for autism: comprehensive meta-analysis. Br J Psychiatry 2009;195:7-14.

8 Yirmiya N, Shaked M. Psychiatric disorders in parents of children with autism: a meta-analysis. J Child Psychol Psychiatry 2005;46:69-83.

9 Magnusson C, Rai D, Goodman A, Lundberg M, Idring S, Svensson A, et al. Migration and autism spectrum disorder: population-based study. Br J Psychiatry 2012;201:109-15.

10 Rai D, Lewis G, Lundberg M, Araya R, Svensson A, Dalman C, et al. Parental socioeconomic status and risk of offspring autism spectrum disorders in a Swedish population-based study. J Am Acad Child Adolesc Psychiatry 2012;51:467-76.

11 Axén M. ADHD, lindrig utvecklingsstörning och autismspektrumtillstånd hos barn, ungdomar och vuxna [ADHD, mild mental retardation and autism spectrum disorders in children, adolescents and adults]. Stockholms läns landsting, 2010.

12 Jorgensen L, Ahlbom A, Allebeck P, Dalman C. The Stockholm non-affective psychoses study (snaps): the importance of including out-patient data in incidence studies. Acta Psychiatr Scand 2010;121:389-92.

13 Quality of data and reporting procedures in the National Patient Register. Discharges from inpatient care 1964-2007 and visits to specialiced outpatient care (excluding primary health care) 1997-2007 [In Swedish]. National Board of Health and Welfare, 2009.

14 World Health Organization. The ICD-10 classification of mental and behavioural disorders diagnostic criteria for research. WHO, 1993.

15 Axelsson O. The Swedish medical birth register. Acta Obstet Gynecol Scand 2003;82:491-2.

16 Kallen B, Nilsson E, Olausson PO. Antidepressant use during pregnancy: comparison of data obtained from a prescription register and from antenatal care records. Eur $\mathrm{J}$ Clin Pharmacol 2011;67:839-45.

17 Stephansson O, Granath F, Svensson T, Haglund B, Ekbom A, Kieler H. Drug use during pregnancy in Sweden—assessed by the Prescribed Drug Register and the Medical Birth Register. Clin Epidemiol 2011;3:43-50.

18 Kolevzon A, Gross R, Reichenberg A. Prenatal and perinatal risk factors for autism: a review and integration of findings. Arch Pediatr Adolesc Med 2007:161:326-33.

19 Abel KM, Dalman C, Svensson A, Susser E, Dal H, Idring S, et al. Deviance in fetal growth and risk of autism spectrum disorder. Am J Psychiatry 2013;170:391-8.

20 Lee BK, Gardner RM, Dal H, Svensson A, Galanti MR, Rai D, et al. Brief report: maternal smoking during pregnancy and autism spectrum disorders. J Autism Dev Disord 2012;42:2000-5.

21 Gardener H, Spiegelman D, Buka SL. Perinatal and neonatal risk factors for autism: a comprehensive meta-analysis. Pediatrics 2011;128:344-55.

22 El Marroun H, Jaddoe VW, Hudziak JJ, Roza SJ, Steegers EA, Hofman A, et al. Maternal use of selective serotonin reuptake inhibitors, fetal growth, and risk of adverse birth outcomes. Arch Gen Psychiatry 2012;69:706-14.

23 Schisterman EF, Cole SR, Platt RW. Overadjustment bias and unnecessary adjustment in epidemiologic studies. Epidemiology 2009:20:488-95.

24 Jokiranta E, Brown AS, Heinimaa M, Cheslack-Postava K, Suominen A, Sourander A. Parental psychiatric disorders and autism spectrum disorders. Psychiatry Res 2013; published online $4 \mathrm{Feb}$.

25 Lauritsen MB, Pedersen CB, Mortensen PB. Effects of familial risk factors and place of birth on the risk of autism: a nationwide register-based study. $J$ Child Psychol Psychiatry 2005;46:963-71.

26 Larsson HJ, Eaton WW, Madsen KM, Vestergaard M, Olesen AV, Agerbo E, et al. Risk factors for autism: perinatal factors, parental psychiatric history, and socioeconomic status. Am J Epidemiol 2005;161:916-25.

27 Zafeiriou DI, Ververi A, Vargiami E. The serotonergic system: its role in pathogenesis and early developmental treatment of autism. Curr Neuropharmacol 2009;7:150-7.

28 Chadman KK. Fluoxetine but not risperidone increases sociability in the BTBR mouse model of autism. Pharmacol Biochem Behav 2011;97:586-94.

29 Darling RD, Alzghoul L, Zhang JL, Khatri N, Paul IA, Simpson KL, et al. Perinatal citalopram exposure selectively increases locus ceruleus circuit function in male rats. $J$ Neurosci 2011;31:16709-15.

30 Rodriguez-Porcel F, Green D, Khatri N, Harris SS, May WL, Lin RCS, et al. Neonatal exposure of rats to antidepressants affects behavioral reactions to novelty and social interactions in a manner analogous to autistic spectrum disorders. Anat Rec (Hoboken) 2011;294:1726-35

31 Simpson KL, Weaver KJ, de Villers-Sidani E, Lu JYF, Cai ZW, Pang Y, et al. Perinatal antidepressant exposure alters cortical network function in rodents. Proc Natl Acad Sci USA 2011;108:18465-70.

32 Boyer EW, Shannon M. The serotonin syndrome. N Engl J Med 2005;352:1112-20.

33 Kinney DK, Munir KM, Crowley DJ, Miller AM. Prenatal stress and risk for autism. Neurosci Biobehav Rev 2008;32:1519-32.

34 Rai D, Golding J, Magnusson C, Steer C, Lewis G, Dalman C. Prenatal and early life exposure to stressful life events and risk of autism spectrum disorders: population-based studies in sweden and England. PloS One 2012;7:e38893.

35 Maes M. Depression is an inflammatory disease, but cell-mediated immune activation is the key component of depression. Prog Neuropsychopharmacol Biol Psychiatry 2011;35:664-75

36 Onore C, Careaga M, Ashwood P. The role of immune dysfunction in the pathophysiology of autism. Brain Behav Immun 2012;26:383-92.

37 Delong GR. Autism: new data suggest a new hypothesis. Neurology 1999;52:911-6.

38 Greenland S. The effect of misclassification in the presence of covariates. Am J Epidemiol 1980;112:564-9. 


\section{What is already known on this topic}

Parental depression is considered a risk factor for autism spectrum disorder (autism) but meta-analytical evidence is inconclusive One study suggested an association between prescriptions for selective serotonin reuptake inhibitors (SSRIs) during pregnancy and autism in offspring

This suggestion may have led to a preferential use of other antidepressants over SSRIs during pregnancy

\section{What this study adds}

A maternal but not paternal history of depression was associated with a higher risk of autism in offspring

The increased risk of autism was largely found in children of mothers reporting antidepressant use at the first antenatal interview. However, SSRIs as well as non-selective monoamine reuptake inhibitors were associated with increased risks for autism, suggesting non-SSRIs may not be "safer" alternatives in this context.

Associations were largely limited to autism without intellectual disability, suggesting that autism with and without intellectual disability may have partially different causes

39 Ogburn EL, VanderWeele TJ. On the nondifferential misclassification of a binary confounder. Epidemiology 2012;23:433-9.

40 Stewart DE. Clinical practice. Depression during pregnancy. N Engl J Med 2011;365:1605-11.

41 Spinelli M. Antidepressant treatment during pregnancy. Am J Psychiatry 2012;169:121-4.

42 Rahimi R, Nikfar S, Abdollahi M. Pregnancy outcomes following exposure to serotonin reuptake inhibitors: a meta-analysis of clinical trials. Reprod Toxicol 2006;22:571-5.

43 Lund N, Pedersen LH, Henriksen TB. Selective serotonin reuptake inhibitor exposure in utero and pregnancy outcomes. Arch Pediatr Adolesc Med 2009;163:949-54.

44 Oberlander TF, Warburton W, Misri S, Aghajanian J, Hertzman C. Neonatal outcomes after prenatal exposure to selective serotonin reuptake inhibitor antidepressants and maternal depression using population-based linked health data. Arch Gen Psychiatry 2006:63:898-906.

45 Reis M, Kallen B. Delivery outcome after maternal use of antidepressant drugs in pregnancy: an update using Swedish data. Psychol Med 2010;40:1723-33.
46 Occhiogrosso M, Omran SS, Altemus M. Persistent pulmonary hypertension of the newborn and selective serotonin reuptake inhibitors: lessons from clinical and translational studies. Am J Psychiatry 2012;169:134-40.

Accepted: 12 March 2013

\section{Cite this as: BMJ 2013:346:f2059}

This is an Open Access article distributed in accordance with the Creative Commons Attribution Non Commercial (CC BY-NC 3.0) license, which permits others to distribute, remix, adapt, build upon this work non-commercially, and license their derivative works on different terms, provided the original work is properly cited and the use is non-commercial. See: http://creativecommons.org/licenses/by-nc/3.0/. 


\section{Tables}

Table 1| Descriptive characteristics of cases of autism spectrum disorder and controls in complete case sample (current paper), and full sample with all available data

\begin{tabular}{|c|c|c|c|c|c|c|}
\hline \multirow[b]{2}{*}{ Characteristics } & \multicolumn{3}{|c|}{ Complete case sample ${ }^{*}$} & \multicolumn{3}{|c|}{ Full sample } \\
\hline & Cases & Controls & $\mathbf{P}$ valuet & Cases & Controls & $\mathrm{P}$ value \\
\hline Cases with autism spectrum disorder & $\mathrm{n}=4429$ & $\mathrm{n}=43277$ & & $\mathrm{n}=4952$ & $n=49520$ & \\
\hline Maternal depression & 1.0 & 0.6 & 0.004 & 1.0 & 0.6 & 0.001 \\
\hline Paternal depression & 0.4 & 0.4 & 0.439 & 0.4 & 0.3 & 0.499 \\
\hline \multicolumn{7}{|l|}{ Maternal history of other psychiatric disorders $¥:$} \\
\hline Anxiety disorder & 0.9 & 0.6 & 0.055 & 0.9 & 0.6 & 0.016 \\
\hline Psychotic disorders & 0.8 & 0.3 & $<0.001$ & 0.7 & 0.3 & $<0.001$ \\
\hline Other psychiatric disorder & 2.1 & 1.0 & $<0.001$ & 1.9 & 0.9 & $<0.001$ \\
\hline \multicolumn{7}{|l|}{ Paternal history of other psychiatric disordersł: } \\
\hline Anxiety disorder & 0.4 & 0.3 & 0.120 & 0.4 & 0.3 & 0.133 \\
\hline Psychotic disorder & 0.7 & 0.3 & $<0.001$ & 0.7 & 0.3 & $<0.001$ \\
\hline Other psychiatric disorder & 2.4 & 1.3 & $<0.001$ & 2.3 & 1.2 & $<0.001$ \\
\hline Mean (SD) maternal age (years)§ & $29.7(5.5)$ & $29.5(5.1)$ & $<0.001$ & $29.7(5.5)$ & $29.3(5.2)$ & $<0.001$ \\
\hline Mean (SD) paternal age (years)§ & $32.7(6.7)$ & $32.4(6.3)$ & $<0.001$ & $32.8(6.7)$ & $32.4(6.3)$ & $<0.001$ \\
\hline \multicolumn{7}{|l|}{ Family income: } \\
\hline 1st fifth (highest) & 17.4 & 21.3 & \multirow[t]{2}{*}{$<0.001$} & 16.8 & 19.9 & \multirow[t]{2}{*}{$<0.001$} \\
\hline 5th fifth (lowest) & 16.7 & 15.5 & & 19.4 & 20.1 & \\
\hline \multicolumn{7}{|l|}{ Parental education: } \\
\hline$>12$ years & 45.9 & 48.8 & \multirow[t]{3}{*}{0.001} & 46.1 & 48.4 & \multirow[t]{3}{*}{0.006} \\
\hline $10-12$ years & 46.5 & 43.9 & & 45.6 & 43.2 & \\
\hline$<9$ years & 7.6 & 7.3 & & 8.3 & 8.4 & \\
\hline \multicolumn{7}{|l|}{ Occupational class: } \\
\hline Higher professionals & 17.6 & 19.0 & \multirow[t]{7}{*}{$<0.001$} & 16.7 & 17.7 & \multirow[t]{7}{*}{$<0.001$} \\
\hline Intermediate non-manual employees & 18.1 & 20.7 & & 17.4 & 19.1 & \\
\hline Lower non-manual employees & 13.6 & 15.0 & & 13.1 & 14.0 & \\
\hline Skilled manual workers & 15.8 & 14.3 & & 15.2 & 13.4 & \\
\hline Unskilled manual workers & 17.7 & 13.8 & & 17.3 & 13.6 & \\
\hline Self employed & 3.9 & 4.9 & & 3.8 & 4.6 & \\
\hline Unclassified & 13.3 & 12.3 & & 16.5 & 17.7 & \\
\hline \multicolumn{7}{|l|}{ Maternal country of birth: } \\
\hline Sweden & 77.5 & 78.4 & \multirow[t]{5}{*}{$<0.001$} & 74.4 & 73.2 & \multirow[t]{5}{*}{$<0.001$} \\
\hline Europe & 9.4 & 8.5 & & 10.5 & 9.6 & \\
\hline Americas & 3.1 & 2.3 & & 3.4 & 2.8 & \\
\hline Africa & 3.1 & 2.1 & & 3.4 & 2.9 & \\
\hline Asia or Oceania & 6.9 & 8.7 & & 8.3 & 11.5 & \\
\hline \multicolumn{7}{|l|}{ Parity (previous births): } \\
\hline 0 & 47.5 & 44.28 & \multirow[t]{4}{*}{$<0.001$} & 47.6 & 44.4 & \multirow[t]{4}{*}{$<0.001$} \\
\hline 1 & 33.2 & 35.9 & & 33.2 & 35.6 & \\
\hline 2 & 13.2 & 14.1 & & 13.2 & 14.1 & \\
\hline$\geq 3$ & 6.1 & 5.7 & & 6.0 & 5.9 & \\
\hline Cases of autism spectrum disorder without intellectual disability & $\mathrm{n}=2601$ & $n=24986$ & & $\mathrm{n}=2855$ & $n=28550$ & \\
\hline Maternal depression & 1.2 & 0.6 & $<0.001$ & 1.2 & 0.6 & $<0.001$ \\
\hline Paternal depression & 0.4 & 0.4 & 0.893 & 0.4 & 0.3 & 0.987 \\
\hline \multicolumn{7}{|l|}{ Maternal history of other psychiatric disordersł: } \\
\hline Anxiety disorder & 1.0 & 0.6 & 0.029 & 1.0 & 0.6 & 0.023 \\
\hline
\end{tabular}


Table 1 (continued)

\begin{tabular}{|c|c|c|c|c|c|c|}
\hline \multirow[b]{2}{*}{ Characteristics } & \multicolumn{3}{|c|}{ Complete case sample* } & \multicolumn{3}{|c|}{ Full sample } \\
\hline & Cases & Controls & $P$ valuet & Cases & Controls & $P$ value \\
\hline Psychotic disorders & 0.7 & 0.3 & 0.004 & 0.6 & 0.3 & 0.003 \\
\hline Other psychiatric disorder & 2.2 & 1.0 & $<0.001$ & 2.1 & 0.9 & $<0.001$ \\
\hline \multicolumn{7}{|l|}{ Paternal history of other psychiatric disorders $¥:$} \\
\hline Anxiety disorder & 0.5 & 0.3 & 0.066 & 0.4 & 0.3 & 0.082 \\
\hline Psychotic disorder & 0.4 & 0.3 & 0.338 & 0.4 & 0.3 & 0.187 \\
\hline Other psychiatric disorder & 2.5 & 1.3 & $<0.001$ & 2.5 & 1.2 & $<0.001$ \\
\hline Mean (SD) maternal age (years)§ & $29.4(5.5)$ & $29.5(5.1)$ & 0.001 & $29.5(5.5)$ & $29.3(5.2)$ & 0.021 \\
\hline Mean (SD) paternal age (years)§ & $32.2(6.5)$ & $32.4(6.3)$ & 0.003 & $32.3(6.5)$ & $32.4(6.3)$ & 0.026 \\
\hline \multicolumn{7}{|l|}{ Family income: } \\
\hline 1st fifth (highest) & 17.7 & 21.3 & \multirow[t]{2}{*}{$<0.001$} & 17.4 & 19.8 & \multirow[t]{2}{*}{$<0.001$} \\
\hline 5th fifth (lowest) & 14.6 & 15.5 & & 16.2 & 20.3 & \\
\hline \multicolumn{7}{|l|}{ Parental education: } \\
\hline$>12$ years & 46.1 & 48.3 & \multirow[t]{3}{*}{0.037} & 46.4 & 47.9 & \multirow[t]{3}{*}{0.021} \\
\hline $10-12$ years & 46.8 & 44.1 & & 45.9 & 43.4 & \\
\hline$<9$ years & 7.2 & 7.6 & & 7.7 & 8.7 & \\
\hline \multicolumn{7}{|l|}{ Occupational class: } \\
\hline Higher professionals & 17.1 & 19.0 & \multirow[t]{7}{*}{$<0.001$} & 16.4 & 17.6 & \multirow[t]{7}{*}{$<0.001$} \\
\hline Intermediate non-manual employees & 19.5 & 20.6 & & 19.1 & 19.0 & \\
\hline Lower non-manual employees & 14.4 & 15.1 & & 13.9 & 14.2 & \\
\hline Skilled manual workers & 15.9 & 14.5 & & 15.6 & 13.5 & \\
\hline Unskilled manual workers & 17.7 & 13.9 & & 17.6 & 13.6 & \\
\hline Self employed & 3.5 & 4.9 & & 3.4 & 4.6 & \\
\hline Unclassified & 11.9 & 12.0 & & 14.0 & 17.5 & \\
\hline \multicolumn{7}{|l|}{ Maternal country of birth: } \\
\hline Sweden & 82.6 & 78.2 & \multirow[t]{5}{*}{$<0.001$} & 80.7 & 73.0 & \multirow[t]{5}{*}{$<0.001$} \\
\hline Europe & 9.2 & 8.6 & & 10.1 & 9.6 & \\
\hline Americas & 2.6 & 2.5 & & 2.8 & 2.9 & \\
\hline Africa & 1.1 & 2.0 & & 1.1 & 2.9 & \\
\hline Asia or Oceania & 4.5 & 8.7 & & 5.3 & 11.6 & \\
\hline \multicolumn{7}{|l|}{ Parity (previous births): } \\
\hline 0 & 51.2 & 44.1 & \multirow[t]{4}{*}{$<0.001$} & 51.3 & 44.3 & \multirow[t]{4}{*}{$<0.001$} \\
\hline 1 & 31.6 & 36.0 & & 31.4 & 35.7 & \\
\hline 2 & 11.9 & 14.0 & & 12.0 & 14.1 & \\
\hline$\geq 3$ & 5.3 & 5.8 & & 5.4 & 6.0 & \\
\hline Autism spectrum disorder cases with intellectual disability & $\mathrm{n}=1828$ & $\mathrm{n}=18291$ & & $\mathrm{n}=2097$ & $n=20970$ & \\
\hline Maternal depression & 0.7 & 0.7 & 0.950 & 0.6 & 0.6 & 0.870 \\
\hline Paternal depression & 0.5 & 0.3 & 0.293 & 0.3 & 0.4 & 0.362 \\
\hline \multicolumn{7}{|l|}{ Maternal history of other psychiatric disorderł: } \\
\hline Anxiety disorder & 0.7 & 0.6 & 0.739 & 0.7 & 0.5 & 0.314 \\
\hline Psychotic disorder & 0.9 & 0.3 & $<0.001$ & 0.8 & 0.3 & $<0.001$ \\
\hline Other psychiatric disorder & 1.9 & 1.0 & $<0.001$ & 1.7 & 0.9 & $<0.001$ \\
\hline \multicolumn{7}{|l|}{ Paternal history of other psychiatric disorderł: } \\
\hline Anxiety disorder & 0.3 & 0.3 & 0.813 & 0.3 & 0.3 & 0.793 \\
\hline Psychotic disorder & 1.2 & 0.3 & $<0.001$ & 1.0 & 0.3 & $<0.001$ \\
\hline Other psychiatric disorder & 2.1 & 1.2 & 0.002 & 1.9 & 1.2 & 0.002 \\
\hline Mean (SD) maternal age (years)§ & $30.0(5.5)$ & $29.5(5.1)$ & $<0.001$ & $29.9(5.6)$ & $29.4(5.2)$ & $<0.001$ \\
\hline Mean (SD) paternal age (years)§ & $33.3(6.8)$ & $32.3(6.2)$ & $<0.001$ & $33.4(6.8)$ & $32.4(6.3)$ & $<0.001$ \\
\hline
\end{tabular}




\section{Table 1 (continued)}

\begin{tabular}{|c|c|c|c|c|c|c|}
\hline \multirow[b]{2}{*}{ Characteristics } & \multicolumn{3}{|c|}{ Complete case sample* } & \multicolumn{3}{|c|}{ Full sample } \\
\hline & Cases & Controls & $\mathbf{P}$ valuet & Cases & Controls & $\mathbf{P}$ value \\
\hline \multicolumn{7}{|l|}{ Family income: } \\
\hline 1st fifth (highest) & 16.9 & 21.4 & \multirow[t]{2}{*}{$<0.001$} & 16.1 & 20.1 & \multirow[t]{2}{*}{$<0.001$} \\
\hline 5th fifth (lowest) & 19.8 & 15.5 & & 23.7 & 20.0 & \\
\hline \multicolumn{7}{|l|}{ Parental education: } \\
\hline$>12$ years & 45.7 & 49.4 & \multirow{3}{*}{0.006} & 45.8 & 49.2 & \multirow[t]{3}{*}{0.010} \\
\hline $10-12$ years & 46.2 & 43.7 & & 45.0 & 42.9 & \\
\hline$<9$ years & 8.2 & 6.9 & & 9.2 & 8.0 & \\
\hline \multicolumn{7}{|l|}{ Occupational class: } \\
\hline Higher professionals & 18.4 & 18.9 & \multirow[t]{7}{*}{$<0.001$} & 17.2 & 17.7 & \multirow[t]{7}{*}{$<0.001$} \\
\hline Intermediate non-manual & 16.0 & 20.8 & & 15.2 & 19.2 & \\
\hline Lower non-manual employees & 12.4 & 14.8 & & 11.8 & 13.8 & \\
\hline Skilled manual workers & 15.7 & 14.0 & & 14.6 & 13.1 & \\
\hline Unskilled manual workers & 17.7 & 13.8 & & 16.9 & 13.5 & \\
\hline Self employed & 4.4 & 4.9 & & 4.2 & 4.6 & \\
\hline Unclassified & 15.4 & 12.8 & & 20.0 & 18.1 & \\
\hline \multicolumn{7}{|l|}{ Maternal country of birth: } \\
\hline Sweden & 70.4 & 78.7 & \multirow[t]{5}{*}{$<0.001$} & 66.0 & 73.5 & \multirow[t]{5}{*}{$<0.001$} \\
\hline Europe & 9.7 & 8.4 & & 11.0 & 9.5 & \\
\hline Americas & 3.7 & 2.2 & & 4.2 & 2.7 & \\
\hline Africa & 6.0 & 2.1 & & 6.6 & 2.8 & \\
\hline Asia or Oceania & 10.3 & 8.6 & & 12.3 & 11.4 & \\
\hline \multicolumn{7}{|l|}{ Parity (previous births): } \\
\hline 0 & 42.3 & 44.5 & \multirow[t]{4}{*}{0.027} & 42.5 & 44.6 & \multirow[t]{4}{*}{0.116} \\
\hline 1 & 35.6 & 35.8 & & 35.7 & 35.5 & \\
\hline 2 & 15.0 & 14.2 & & 14.9 & 14.2 & \\
\hline$\geq 3$ & 7.1 & 5.5 & & 6.9 & 5.7 & \\
\hline
\end{tabular}

*No missing data in any variables.

†P values derived from conditional logistic regression to account for matching of cases and controls by age and sex. ¥History of psychiatric disorders refers to specialist outpatient or inpatient psychiatric care.

$\S$ Ages are categorised in paper. 
Table 2| Odds ratios depicting relation between parental depression before birth of child and autism spectrum disorder and autism spectrum disorder with and without intellectual disability in children born between 1984 and 2003

\begin{tabular}{|c|c|c|c|c|c|}
\hline \multirow[b]{2}{*}{ Variables } & \multirow{2}{*}{$\begin{array}{c}\text { No of } \\
\text { cases/controls }\end{array}$} & \multirow{2}{*}{$\begin{array}{l}\text { Crude odds ratio }(95 \% \\
\text { Cl) }\end{array}$} & \multicolumn{3}{|c|}{ Odds ratio $(95 \% \mathrm{Cl})$} \\
\hline & & & Model 1* & Model 2† & Model 3‡ \\
\hline \multicolumn{6}{|l|}{ Maternal depression: } \\
\hline Autism spectrum disorder & $44 / 272$ & 1.61 (1.17 to 2.23$)$ & 1.50 (1.08 to 2.08$)$ & 1.54 (1.11 to 2.13 ) & 1.49 (1.08 to 2.08$)$ \\
\hline $\begin{array}{l}\text { Autism spectrum disorder with } \\
\text { intellectual disability }\end{array}$ & $12 / 121$ & $1.02(0.56$ to 1.86$)$ & $0.96(0.52$ to 1.76$)$ & $0.98(0.53$ to 1.80$)$ & $0.96(0.52$ to 1.77$)$ \\
\hline $\begin{array}{l}\text { Autism spectrum disorder } \\
\text { without intellectual disability }\end{array}$ & $32 / 151$ & 2.07 (1.40 to 3.06$)$ & 1.85 (1.24 to 2.74$)$ & 1.90 (1.28 to 2.82$)$ & $1.86(1.25$ to 2.77$)$ \\
\hline \multicolumn{6}{|l|}{ Paternal depression: } \\
\hline Autism spectrum disorder & $19 / 155$ & $1.21(0.75$ to 1.96$)$ & $1.11(0.68$ to 1.79$)$ & $1.13(0.70$ to 1.83$)$ & $1.12(0.69$ to 1.82$)$ \\
\hline $\begin{array}{l}\text { Autism spectrum disorder with } \\
\text { intellectual disability }\end{array}$ & $9 / 63$ & $1.46(0.72$ to 2.96$)$ & 1.33 (0.65 to 2.72$)$ & $1.36(0.67$ to 2.78$)$ & 1.35 (0.66 to 2.77$)$ \\
\hline $\begin{array}{l}\text { Autism spectrum disorder } \\
\text { without intellectual disability }\end{array}$ & $10 / 92$ & 1.05 (0.54 to 2.02$)$ & 0.96 (0.50 to 1.87$)$ & $0.98(0.51$ to 1.91$)$ & $0.97(0.50$ to 1.89$)$ \\
\hline
\end{tabular}

Children with autism spectrum disorder: cases $n=4429$, controls $n=43277$.

Children with autism spectrum disorder with intellectual disability: cases $n=1828$, controls $n=18291$.

Children with autism spectrum disorder without intellectual disability: cases $n=2601$, controls $n=24986$.

*Adjusted for parental ages, income, education, occupation, migration status, and parity.

†Model 1 further adjusted for any other psychiatric condition (including anxiety disorders, affective (bipolar) and non affective psychoses (schizophrenia), somatoform, neurodevelopmental, and personality or drug and alcohol misuse disorders).

¥Model 2 further adjusted for depression in both parents and other psychiatric condition in both parents. 
Table 3 | Odds ratios depicting relation between maternal depression before birth of child and autism spectrum disorder in offspring, adjusting for antidepressant use during pregnancy in children born between 1995 and 2003

\begin{tabular}{|c|c|c|c|c|c|}
\hline \multirow[b]{2}{*}{ Disorder type in offspring } & \multirow[b]{2}{*}{ No of cases/controls } & \multirow[b]{2}{*}{ Crude odds ratio $(95 \% \mathrm{Cl})$} & \multicolumn{3}{|c|}{ Odds ratio $(95 \% \mathrm{Cl})$} \\
\hline & & & Model 1* & Model $2 \dagger$ & Model 3‡ \\
\hline Autism spectrum disorder & $24 / 174$ & 1.40 (0.91 to 2.17$)$ & $1.24(0.79$ to 1.94$)$ & 1.34 (0.87 to 2.08$)$ & 1.19 (0.76 to 1.87$)$ \\
\hline $\begin{array}{l}\text { Autism spectrum disorder with intellectual } \\
\text { disability }\end{array}$ & $9 / 85$ & 1.09 (0.54 to 2.20$)$ & $1.08(0.53$ to 2.20$)$ & $1.06(0.52$ to 2.16$)$ & $1.04(0.50$ to 2.13$)$ \\
\hline $\begin{array}{l}\text { Autism spectrum disorder without intellectual } \\
\text { disability }\end{array}$ & $15 / 89$ & 1.69 (0.97 to 2.97$)$ & 1.35 (0.75 to 2.45$)$ & $1.58(0.90$ to 2.79$)$ & $1.30(0.72$ to 2.34$)$ \\
\hline
\end{tabular}

Children with autism spectrum disorder: cases $n=1679$, controls $n=16845$.

Children with autism spectrum disorder with intellectual disability: cases $n=743$, controls $n=7584$.

Children with autism spectrum disorder without intellectual disability: cases $n=936$, controls $n=9261$.

*Adjusted for antidepressant use only during pregnancy.

†Adjusted for parental ages, income, education, occupation, migration status, and parity.

¥Model 2 adjusted for antidepressant use during pregnancy. 
Table 4 | Odds ratios depicting relation between maternal depression, antidepressant use during pregnancy, and autism spectrum disorder in offspring (with and without intellectual disability) in children born between 1995 and 2003

\begin{tabular}{|c|c|c|c|c|c|c|c|c|c|}
\hline \multirow[b]{2}{*}{ Variables } & \multicolumn{3}{|c|}{ Autism spectrum disorder } & \multicolumn{3}{|c|}{$\begin{array}{l}\text { Autism spectrum disorder with } \\
\text { intellectual disability }\end{array}$} & \multicolumn{3}{|c|}{$\begin{array}{l}\text { Autism spectrum disorder without } \\
\text { intellectual disability }\end{array}$} \\
\hline & $\begin{array}{c}\text { No of } \\
\text { cases/controls }\end{array}$ & $\begin{array}{c}\text { Crude } \\
\text { odds ratio } \\
(95 \% \mathrm{Cl})\end{array}$ & $\begin{array}{c}\text { Adjusted } \\
\text { odds ratio* } \\
(95 \% \mathrm{CI})\end{array}$ & $\begin{array}{c}\text { No of } \\
\text { cases/controls }\end{array}$ & $\begin{array}{l}\text { Crude odds } \\
\text { ratio }(95 \% \\
\text { CI) }\end{array}$ & $\begin{array}{c}\text { Adjusted } \\
\text { odds ratio* } \\
(95 \% \mathrm{CI})\end{array}$ & $\begin{array}{c}\text { No of } \\
\text { cases/control }\end{array}$ & $\begin{array}{l}\text { Crude odds } \\
\text { ratio }(95 \% \\
\text { Cl) }\end{array}$ & $\begin{array}{c}\text { Adjusted } \\
\text { odds ratio* } \\
(95 \% \mathrm{Cl})\end{array}$ \\
\hline \multicolumn{10}{|l|}{$\begin{array}{l}\text { No } \\
\text { antidepressant } \\
\text { use: }\end{array}$} \\
\hline No depression & $1634 / 16558$ & $\begin{array}{c}1.00 \\
\text { (reference) }\end{array}$ & $\begin{array}{c}1.00 \\
\text { (reference) }\end{array}$ & $727 / 7446$ & $\begin{array}{c}1.00 \\
\text { (reference) }\end{array}$ & $\begin{array}{c}1.00 \\
\text { (reference) }\end{array}$ & $907 / 9112$ & $\begin{array}{c}1.00 \\
\text { (reference) }\end{array}$ & $\begin{array}{c}1.00 \\
\text { (reference) }\end{array}$ \\
\hline Depression† & $24 / 189$ & $\begin{array}{l}1.29(0.84 \\
\text { to } 1.99)\end{array}$ & $\begin{array}{l}1.06(0.68 \\
\text { to } 1.66)\end{array}$ & $11 / 90$ & $\begin{array}{c}1.28(0.67 \text { to } \\
2.42)\end{array}$ & $\begin{array}{c}1.06(0.54 \text { to } \\
2.07)\end{array}$ & $13 / 99$ & $\begin{array}{c}1.30(0.72 \text { to } \\
2.33)\end{array}$ & $\begin{array}{c}1.04(0.57 \text { to } \\
1.92)\end{array}$ \\
\hline \multicolumn{10}{|l|}{$\begin{array}{l}\text { Antidepressant } \\
\text { use: }\end{array}$} \\
\hline Depression† & $9 / 27$ & $\begin{array}{l}3.69(1.68 \\
\text { to } 8.10)\end{array}$ & $\begin{array}{l}3.34(1.50 \\
\text { to } 7.47)\end{array}$ & $2 / 13$ & $\begin{array}{c}1.69(0.37 \text { to } \\
7.71)\end{array}$ & $\begin{array}{c}1.81(0.39 \text { to } \\
8.56)\end{array}$ & $7 / 14$ & $\begin{array}{c}5.58(2.14 \text { to } \\
14.51)\end{array}$ & $\begin{array}{c}4.94(1.85 \text { to } \\
13.23)\end{array}$ \\
\hline $\begin{array}{l}\text { No } \\
\text { depression } \ddagger\end{array}$ & $12 / 71$ & $\begin{array}{c}1.78(0.95 \\
\text { to } 3.34)\end{array}$ & $\begin{array}{c}1.61(0.85 \\
\text { to } 3.06)\end{array}$ & $3 / 35$ & $\begin{array}{c}0.89 \text { ( } 0.27 \text { to } \\
2.95)\end{array}$ & $\begin{array}{c}0.93 \text { ( } 0.27 \text { to } \\
3.21)\end{array}$ & $9 / 36$ & $\begin{array}{c}2.65 \text { (1.25 to } \\
5.62)\end{array}$ & $\begin{array}{c}2.10(0.97 \text { to } \\
4.57)\end{array}$ \\
\hline
\end{tabular}

*Adjusted for history of psychiatric disorders other than depression, parental ages, income, education, occupation, migration status, and parity.

†Any outpatient (secondary care) or inpatient record of depression before birth of child. Antidepressant use refers to any antidepressant use recorded at first antenatal interview.

$\ddagger$ Psychiatric indication other than depression was identified in 22 out of 83 women reporting use of antidepressants without a record of depression. Others are likely to have been prescribed in primary care but diagnostic information was not available. 
Table 5 | Odds ratios depicting relation between antidepressant use during pregnancy and autism spectrum disorder, and autism spectrum disorder with and without intellectual disability in children born between 1995 and 2003

\begin{tabular}{|c|c|c|c|c|c|c|c|c|c|}
\hline \multirow[b]{2}{*}{$\begin{array}{l}\text { Antidepressant } \\
\text { use }\end{array}$} & \multicolumn{3}{|c|}{ Autism spectrum disorder } & \multicolumn{3}{|c|}{$\begin{array}{l}\text { Autism spectrum disorder with intellectual } \\
\text { disability }\end{array}$} & \multicolumn{3}{|c|}{$\begin{array}{l}\text { Autism spectrum disorder without } \\
\text { intellectual disability }\end{array}$} \\
\hline & $\begin{array}{c}\text { No of } \\
\text { cases/controls }\end{array}$ & $\begin{array}{l}\text { Crude odds } \\
\text { ratio (95\% } \\
\text { Cl) }\end{array}$ & $\begin{array}{c}\text { Adjusted } \\
\text { odds ratio* } \\
(95 \% \mathrm{CI})\end{array}$ & $\begin{array}{c}\text { No of } \\
\text { cases/controls }\end{array}$ & $\begin{array}{l}\text { Crude odds } \\
\text { ratio }(95 \% \mathrm{Cl})\end{array}$ & $\begin{array}{l}\text { Adjusted } \\
\text { odds ratio* } \\
(95 \% \mathrm{Cl})\end{array}$ & $\begin{array}{c}\text { No of } \\
\text { cases/controls }\end{array}$ & $\begin{array}{l}\text { Crude odds } \\
\text { ratio }(95 \% \mathrm{Cl})\end{array}$ & $\begin{array}{c}\text { Adjusted } \\
\text { odds ratio* } \\
(95 \% \mathrm{Cl})\end{array}$ \\
\hline Any & $21 / 98$ & $\begin{array}{c}2.27(1.40 \text { to } \\
3.71)\end{array}$ & $\begin{array}{c}1.90(1.15 \text { to } \\
3.14)\end{array}$ & $5 / 48$ & $\begin{array}{c}1.09(0.43 \text { to } \\
2.79)\end{array}$ & $\begin{array}{c}1.09(0.41 \text { to } \\
2.88)\end{array}$ & $16 / 50$ & $\begin{array}{c}3.42(1.91 \text { to } \\
6.14)\end{array}$ & $\begin{array}{c}2.54(1.37 \text { to } \\
4.68)\end{array}$ \\
\hline SSRIs & $14 / 71$ & $\begin{array}{c}2.03(1.13 \text { to } \\
3.66)\end{array}$ & $\begin{array}{l}1.65(0.90 \text { to } \\
3.03)\end{array}$ & $4 / 39$ & $\begin{array}{l}1.05 \text { (0.37 to } \\
2.98)\end{array}$ & $\begin{array}{l}1.01 \text { ( } 0.34 \text { to } \\
2.98)\end{array}$ & $10 / 32$ & $\begin{array}{l}3.25(1.55 \text { to } \\
6.81)\end{array}$ & $\begin{array}{c}2.34(1.09 \text { to } \\
5.06)\end{array}$ \\
\hline $\begin{array}{l}\text { Non-selective } \\
\text { MRls }\end{array}$ & $6 / 20$ & $\begin{array}{l}3.20(1.26 \text { to } \\
8.12)\end{array}$ & $\begin{array}{c}2.69(1.04 \text { to } \\
6.96)\end{array}$ & $1 / 7$ & $\begin{array}{c}1.48(0.18 \text { to } \\
12.35)\end{array}$ & $\begin{array}{c}1.72(0.20 \text { to } \\
15.03)\end{array}$ & $5 / 13$ & $\begin{array}{c}4.15(1.44 \text { to } \\
11.96)\end{array}$ & $\begin{array}{c}2.93(0.98 \text { to } \\
8.82)\end{array}$ \\
\hline
\end{tabular}

SSRIs=selective serotonin reuptake inhibitors; non-selective MRIs=non-selective monoamine reuptake inhibitors.

*Adjusted for any maternal psychiatric disorder, maternal age, paternal age, parental income, education, occupation, maternal country of birth, and birth parity. 


\section{Figures}

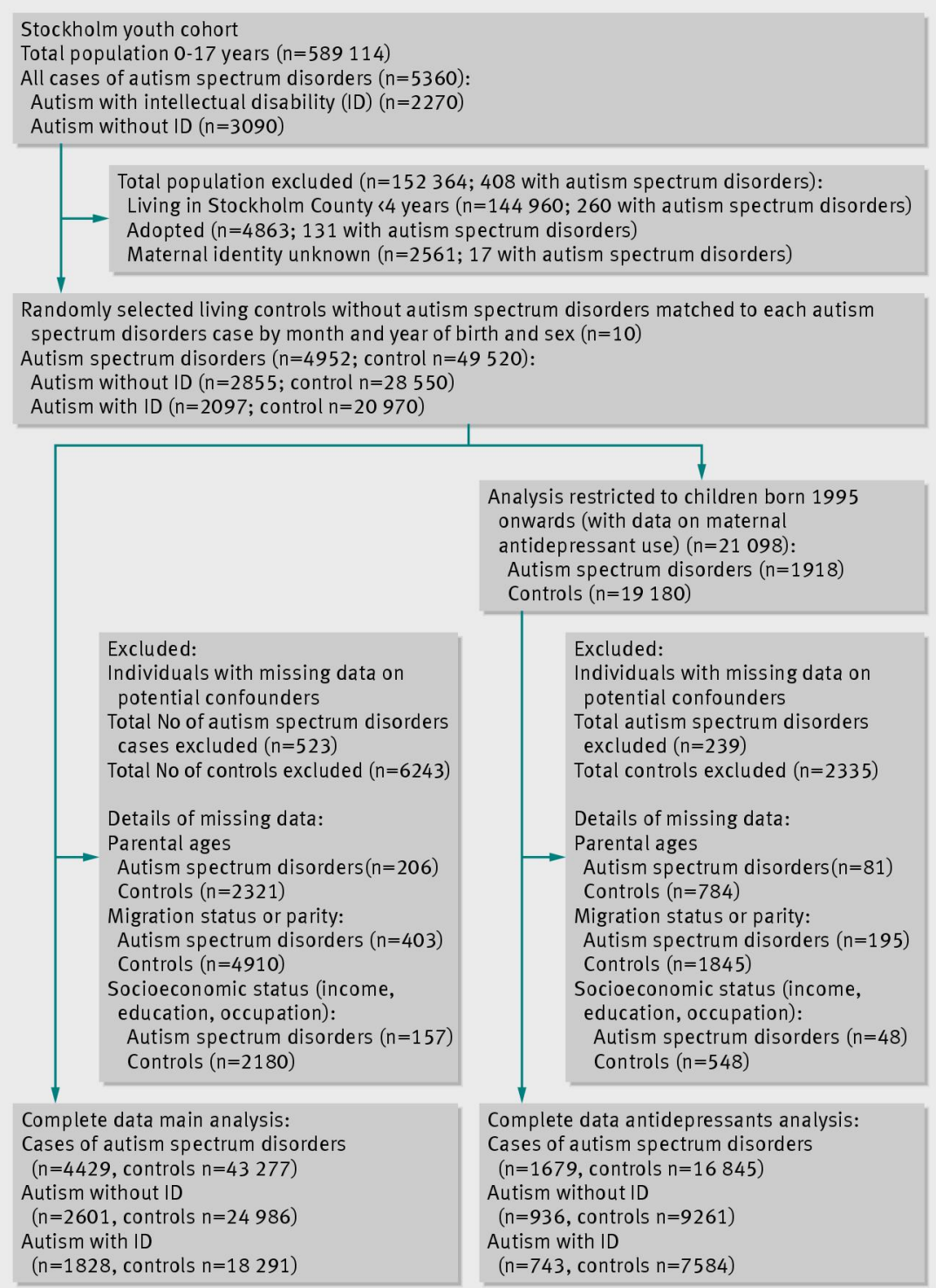

Fig 1 Derivation of analytical sample

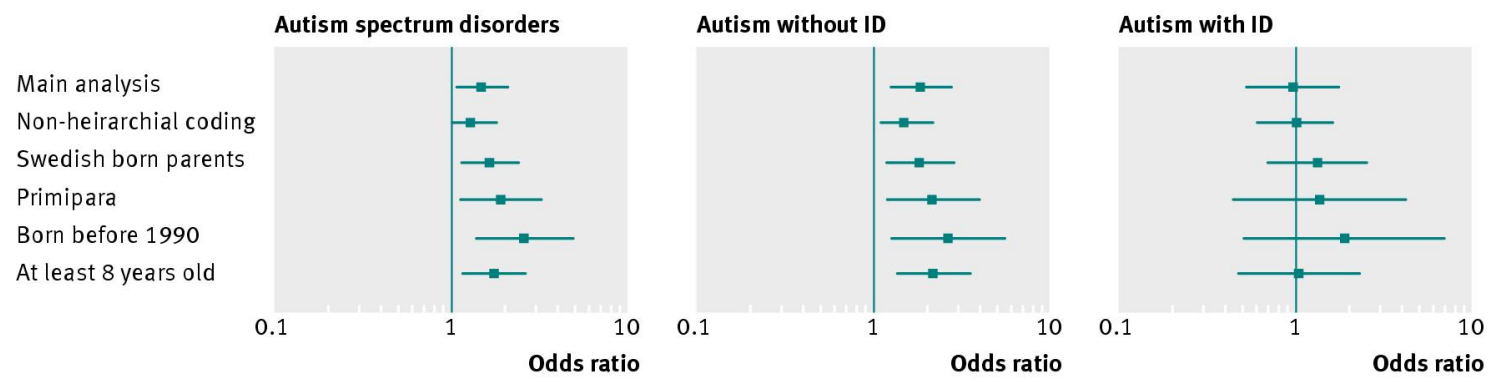

Fig 2 Adjusted odds ratios (95\% confidence intervals) for relation between maternal depression and autism spectrum disorder overall and autism with and without intellectual disability in main and supplementary analyses (tables S3-S7) 